\title{
The Utilisation of Shredded PET as Aggregate Replacement for Interlocking Concrete Block
}

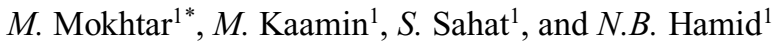 \\ ${ }^{1}$ Department of Civil Engineering, Center for Diploma Studies, Universiti Tun Hussein Onn Malaysia \\ (UTHM), 86400 Parit Raja, Batu Pahat, Johor, Malaysia
}

\begin{abstract}
The consumption of plastic has grown substantially all over the world in recent years and this has created huge quantities of plastic-based waste. Plastic waste is now a serious environmental threat to the modern way of living, although steps were taken to reduce its consumption. This creates substantial garbage every day, which is much unhealthy. Plastic bottles such as Polyethylene terephthalate (PET) was use as the partially component in this making of interlocking blocks concrete. This project investigates the strength and workability of the interlocking block concrete by replacing course aggregate with \% PET. The suitability of recycled plastics (PET) as course aggregate in interlocking block concrete and its advantages are discussed here. Moreover, there were more benefits when using interlocking block than using conventional block such as it easy for construction because they are aligning, easy to place, high speed stacking and they offer more resistance to shear and buildings would be even stronger. Based on the test perform, the failure parameter were discussed .From the compressive strength test result, it shows that the strength of concrete block decreased with increased of PET used. From the results, it shows that higher compressive strength was found with $5 \%$ natural course aggregate replaced with PET compared to other percentages.
\end{abstract}

\section{Introduction}

The interlocking blocks are different from conventional block since they do not require mortar to be laid during bricklaying work. Because of this characteristic, the process of building walls is faster and requires less skilled labour as the blocks are laid dry and lock into place. In addition, the recycled plastics (PET) such as bottles were used to prepare the course aggregates by crushing it to small size thereby providing a sustainable option to deal with the plastic waste.

The normal concrete blocks are inconvenience to use because it takes too long to be stacked, have a low productivity enhancement, high cost and low value of aesthetics. Other than that, plastics are many recycling plants across the world, but as plastics are recycled they lose their strength with the number of recycling. So these plastics will end up as earth fill. In this circumstance instead of recycling it repeatedly, if it is utilized to prepare aggregates for concrete, it will be a boon to the construction industry. Therefore this paper

* Corresponding author: mardiha@uthm.edu.my 
aims to study the ability of interlocking block to replace conventional block in terms of reducing the usage of mortar, to study the effect of replacing natural aggregate with plastic aggregate (PET) on workability and compressive strength and to reduce the density of the block by replacing course aggregate with PET.

\section{Literature Review}

\subsection{Interlocking blocks}

Interlocking blocks are easy to assemble and disassemble. An interlocking lock system for mortarless wall or other structure assembly in which a plurality of blocks are laid up in courses in a staggered relationship [1]. The blocks are configured so that each end of a block comprises a half interlock and adjacent ends of a pair of blocks in a course together define an interlock portion that interlocks with a mating full interlock portion carried by a block in an adjacent course of blocks [2]. Therefore, the main function of interlocking block is to provide better jointing and has enough strength to support the load bearing walls. The interlocking design techniques are also very effective to solve the workmanship problem to ensure the installation of block works is under good quality.

\subsection{Concrete}

Concrete is a product consists of cement, fine and course aggregates and water. The materials are mixed in required proportion to form concrete. For normal mix, the amount of mixture for cement, sand and aggregate is measured by ratio of weight or by ratio of volume. However, ratio by weight is preferable. For example, a mixture of 1:2:4 means 1 part of cement, 2 parts of fine aggregate and 4 parts of course aggregate. Other examples of concrete mixture proportion used to produce the required strength of concrete are 1:3:6, 1: 1.5:3 and 1:4:8. Water use in concrete mixture is based on water/cement ratio, for example 0.5 or 0.6 . Water/cement ratio is a ratio of weight of water to weight of cement used in concrete mixture. The chemical reaction between cement and water causes concrete to harden. When concrete is wet, it will take up the shaped according to mould [3].

\subsection{Polyethylene Terephthalate (PET)}

Polyethylene Terephthalate (PET) is a polymer used for former soft drinks that have full durability [4]. Common types of PET plastic bottles used for mineral water bottles, bottles of soda and shampoo. It is made up of an aromatic ester polymerized into large chains. The chemicals that go into making the PET backbone are ethylene glycol and terephthalic acid [5]. Based on ASTM International Resin Identification Coding System, PET is included in Code 1 in the types of identification codes for plastic. Resin Identification Coding (RIC) is a set of symbols appearing on plastic products that identify the plastic resin out of which the product is made. It was developed originally by the Society of the Plastics Industry (now the Plastics Industry Association) in 1988, but has been administered by ASTM International since 2008 [6].

In the recent years, numerous experimental studies were carried out on using waste PET bottles. Fataniya et al. [7] conducted a study on compressive strength of concrete masonry units with plastic bottle cores and PET fibers. They found that the compressive strength increased up to $2 \%$ replacement of the fine aggregate with PET bottle fibres and it gradually decreased for $4 \%$ and $6 \%$ replacements. Hence replacement of fine aggregate with $2 \%$ replacement was reasonable. Mokhtar et al. [8] have replacing the use of bricks in 
building construction by plastic bottles filled with sand. The results showed that as compared to the clay brick, the maximum stress for $250 \mathrm{ml}$ and 1.5 Liter bottle bricks is higher than the clay bricks for 4 and 3 times respectively which proved that bottle bricks have the potential to replace standard bricks in building. Arivalagan [9] study the possibility of using plastic aggregate as coarse aggregate in concrete. The author found that the modified concrete mix, with addition of plastic aggregate replacing conventional aggregate up to certain $10 \%$ gives strength with in permissible limit.

\section{Materials and methods}

Material for concrete is Portland cement with the ratio of 1:2:4 (cement: sand: aggregate). The materials used for making formwork are plywood because easy to handle and cost effective. These formworks are prepared well before fill with concrete. The design, size and dimension for standard and interlocking block were as shown in Fig. 1.

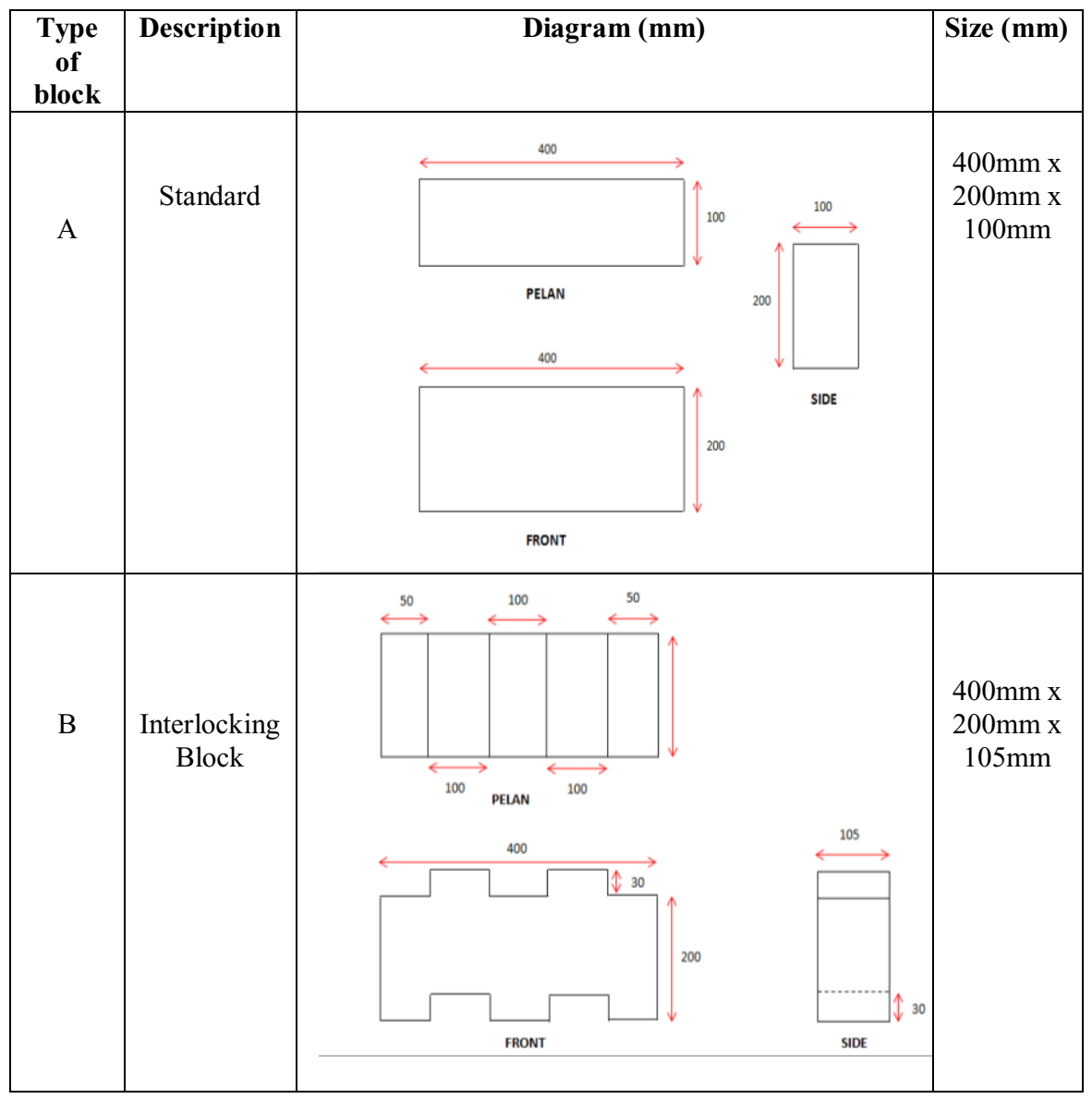

Fig. 1. Design, size and dimension for standard and interlocking block.

Slump test was conducted before the concrete work is carried out. It is the most commonly used method of measuring the consistency of concrete [10]. Changes in the reduction shows the changes in the material, the water content or the content of the mix. 
Therefore, it is useful for quality control of concrete that will be generated. This test was done to obtain the result whether true slump, shear slump or collapse.

Curing is the process to avoid the water content in the concrete evaporates quickly by hot weather. The concrete was put in a damp at least 7 days after it harden. Rather the purpose is to show that high-performance concrete has to be water cured as early as possible, late curing is of partially no value, but is still better that no curing at all, total shrinkage can be drastically reduced by appropriate early water curing and no water curing at all can be catastrophic [11]. Figure 2 shows concrete cube with $0-15 \%$ PET.

\begin{tabular}{|c|c|c|c|c|}
\hline $\begin{array}{c}\text { Type of } \\
\text { Cube }\end{array}$ & Standard & $5 \%$ PET & $10 \%$ PET & $15 \%$ PET \\
\hline Diagram & & & & \\
\hline
\end{tabular}

Fig. 2. Concrete cube with $0-15 \%$ PET.

Compressive strength test was carried out to obtain the strength of the concrete sample. This test was performed by BS 5628: Part 1: 1992. Sample used were concrete sample that had reached the age of 7 days. The main factors affecting the strength of concrete is the number of honeycomb were left in the concrete, the strength will reduced if the concrete more compressible. Therefore, it is imperative that concrete is made as dense as possible. Concrete strength also increases with age, but the rate increases is greatly affected by proper curing methods. Ideally concrete stored in humid conditions to allow the cement hydration occurs properly [12]. Based on the compressive strength results, one of the percentage of PET will be chosen to proceed with construction of standard and interlocking concrete blocks.

\section{Results and discussions}

Slump test was conducted to measure the workability of concrete. Table 1 shows that measured slump decreased with increase in percentage of PET. This result shows that the workability of mixes increase with increase in the percentage of PET.

Through the process of hardening and curing for 7 days of normal concrete cubes and cubes which replaced with $5 \%, 10 \%, 15 \%$ PET, therefore compression tests were carry out to obtain the maximum compressive strength of concrete. Based on the results, the value compressive strength normal cubes were $38.7 \mathrm{MPa}$ with density of $2350 \mathrm{~kg} / \mathrm{m}^{3}$, while the compressive strength of concrete cube with $5 \%$ of PET was $21.5 \mathrm{MPa}$ with a density 2240 $\mathrm{kg} / \mathrm{m}^{3}$. Next, the concrete cube in the mix $10 \%$ PET and $15 \%$ has a compressive strength of 12.7 Mpa and 5.2 Mpa with densities were $2050 \mathrm{~kg} / \mathrm{m}^{3}$ and $1790 \mathrm{~kg} / \mathrm{m}^{3}$. 
Table 1. Slump test results.

\begin{tabular}{|c|c|}
\hline Sample & Slump (mm) \\
\hline Standard & 28 \\
\hline $5 \%$ PET & 21 \\
\hline $10 \%$ PET & 17 \\
\hline $15 \%$ PET & 13 \\
\hline
\end{tabular}

From the results it showed that the more the percentage of PET replaced by aggregate, the compressive strength of concrete decreases. This may occurred with the presents of honeycomb. One of the factors that affect the honeycomb is depend on the water cement ratio. The more value of water cement ratio, the less honey comb appears. Fig. 3 and Fig. 4 shows compressive strength against PET replacement and density against PET replacement. From the results it showed that the implementation usage of PET in concrete mixture had the effects on the strength and density. As stated by Pramod et al [13] in their research on innovative techniques of waste plastic used in concrete mixture, the strength of concrete block decreased with increased of PET used. In addition, the observation when stacking the wall blocks, interlocking blocks concrete with containing PET can saves construction time and less amount usage of mortar compared with conventional blocks. Fig. 5 (a and b) shows samples of standard block concrete and interlocking block concrete.

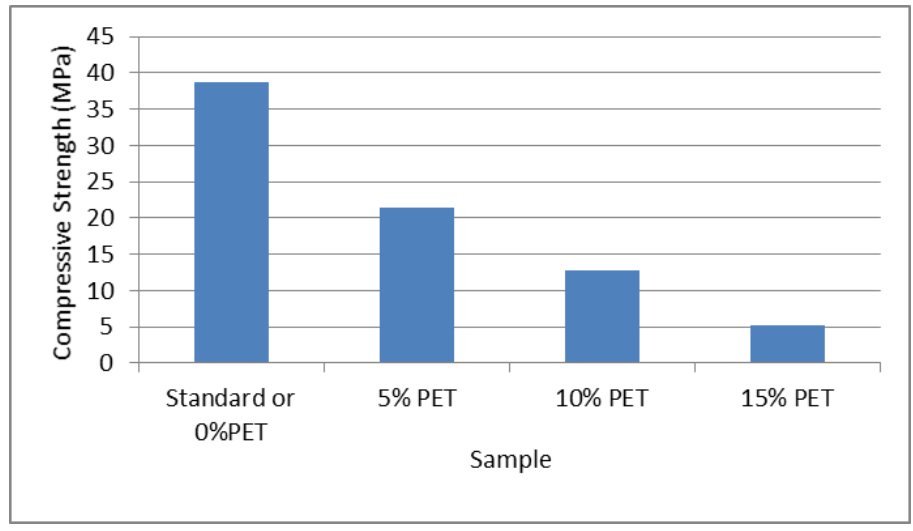

Fig. 3. Compressive strength against PET replacement. 


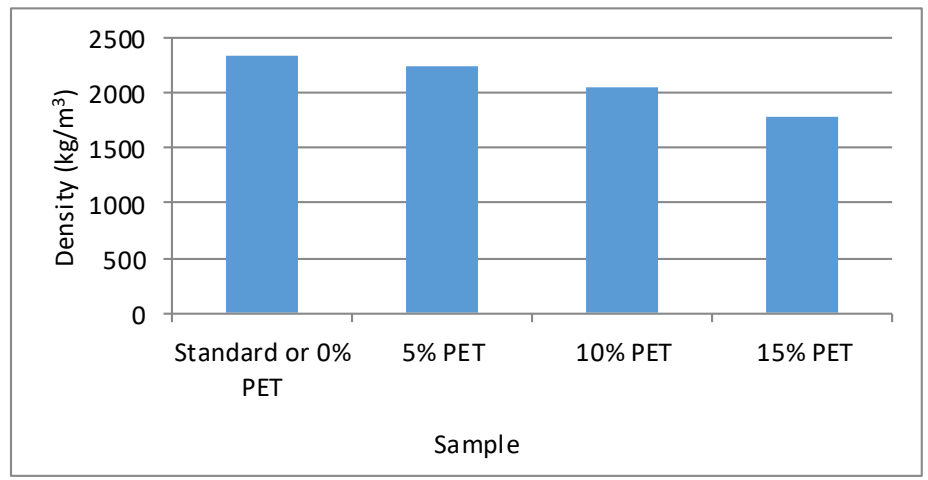

Fig. 4. Density against PET replacement.

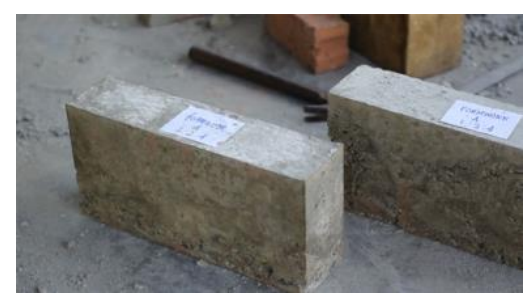

Fig. 5 (a). Samples of standard block concrete.

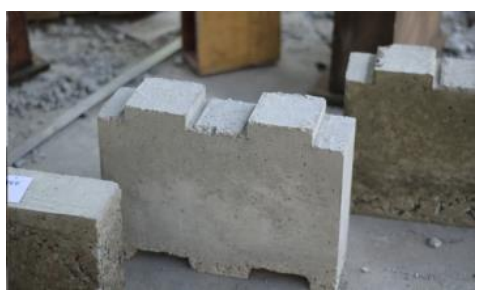

Fig. 5 (b). Samples of interlocking block concrete.

\section{Conclusions}

From the result of this research, the following conclusion can be drawn:

- The more the percentage of PET replaced by aggregate, the compressive strength of concrete decreases.

- The density of concrete decreased when plastic content increased

- By using recycled waste plastic in concrete can reduce the landfill and environmental issues.

- Compared with conventional blocks, the interlocking blocks concrete with containing PET can saves construction time and less amount usage of mortar.

\section{References}

1. Haener Juan, Interlocking Mortarless Building Block System, US 5575128 A. (1996)

2. Timothy A. Bott, Interlcoking Building Block, US6948282 B2 (2005)

3. Yusop bin Paal, Werdah binti Abdul Halim, Sarifah binti Daud, Pengajian Kejuruteraan Awam Tingkatan 4, Dewan Bahasa dan Pustaka (2011)

4. Francisco Casonova-del-Angel and Jorge Luis Vazquez-Ruiz, Manufacturing Light Concrete with PET Aggregate, Article ID 287323 (2012)

5. Paul John Dornath, Analysis of Chemical Leaching from Common Consumer Plastic Bottle Under High Stress Conditions (2010) 
6. ASTM International, ASTM D7611-13 Standard Practice for Coding Plastic Manufactured Articles for Resin Identification (2013)

7. Rakesh Fataniya, Rihan Maaze, Kalpesh Kapadiya \& Vijay F. Pipalia, Experimental IJSRD - International Journal for Scientific Research \& Development 3(4), 2321 (2015)

8. Mokhtar M, Sahat S, Hamid B, Kaamin M, Kesot MJ, Wen LC, Xin L, Ling NP, Lei VS, Journal of Engineering and Applied Sciences 10, 1-5 (2015)

9. Arivalagan.S, International Journal Of Engineering Sciences \& Research Technology 11, 443-449 (2016)

10. Klieger, Paul and Joseph F, Significance of tests and properties of concrete and concrete-making materials, Philadelphia, PA (1994)

11. Aitcin, High-Performance concrete, E.\& F.N. Spon. London (1998)

12. Concrete Block Association, Aggregate Concrete Blocks A Guide to Selection \& Specification, Leicester, United Kingdom, UK (2007)

13. Pramod S. Patil, J.R.Mali, Ganesh V.Tapkire, H. R. Kumavat, Innovative techniques of waste plastic used in concrete mixture (2014) 